\title{
DIREÇÃO E VELOCIDADE DO VENTO EM UMA FLORESTA DE TRANSIÇÃO AMAZÔNIA-CERRADO NO NORTE DE MATO GROSSO, BRASIL
}

\author{
WIND DIRECTION AND SPEED IN AMAZON FOREST SAVANNA \\ TRANSITION IN NORTH MATO GROSSO, BRAZIL
}

\author{
DIRECCIÓN Y VELOCIDAD DEL VIENTO EN UNA TRANSICIÓN \\ AMAZONAS SABANA FORESTAL EN EL NORTE DE MATO GROSSO, BRASIL
}

\author{
Elis Dener Lima Alves - Universidade Federal de Mato Grosso - Cuiabá - Mato Grosso - Brasil \\ elisdener@hotmail.com
}

Stéfano Teixeira Silva - Universidade Federal de Mato Grosso - Cuiabá - Mato Grosso - Brasil silva_stefano@hotmail.com

\begin{abstract}
Resumo
0 objetivo do trabalho foi determinar a direção e a velocidade predominante do vento numa região de floresta tropical de transição Amazônia-Cerrado, localizada a aproximadamente $50 \mathrm{~km}$ da cidade de Sinop, norte de Mato Grosso, Brasil. As direções e velocidades diárias do vento foram coletadas por um anemômetro-termômetro sônico tridimensional, instalado em uma torre a uma altura de $12 \mathrm{~m}$ acima do topo da floresta. A direção predominante do vento foi caracterizada por meio de uma análise de frequência das observações diárias, para cada uma das estações e meses do ano. Na maior parte do ano, há predominância de ventos de sul-sudeste e sul-sudoeste. Observou-se que não houve uma relação direta entre os horários e a direção do vento, tendo 0 mesmo apresentando uma variação sazonal, havendo uma relação direta apenas com a velocidade do vento. $\mathrm{Na}$ estação seca, observou-se que a direção predominante do vento foi de sul-sudoeste. Já nas estações secaúmida e úmida, os ventos fluíram em todas as direções.
\end{abstract}

Palavras-chave: Velocidade do vento, direção do vento, anemômetro.

\section{Abstract}

The objective of the work was to determine the predominant wind direction and speed in a region of rain AmazonSavanna transition forest, located approximately $50 \mathrm{~km}$ from the city of Sinop, in northern Mato Grosso, Brazil. The daily directions wind and speeds were collected by a three-dimensional sonic anemometer-thermometer, installed in a tower at a height of $12 \mathrm{~m}$ above the forest canopy. The predominant wind direction was characterized by a frequency analysis of the daily observations, for each one of the stations and months of the year. In most of the year there is predominance of south-southeast and south-southwest winds. It was observed that there was no direct relation between the time and the wind direction, and the same showing a seasonal variation, there is a direct relation just with the wind speed. In the dry season showed that the predominant wind direction was south-southwest. Already in dry-wet and wet seasons the winds flowed in all directions.

Key words: Wind speed, wind direction, anemometer.

\section{Resumen}

El objetivo fue determinar la dirección y velocidad del viento predominante en una región de la selva tropical del transición Amazonas-Cerrado, situado a unos $50 \mathrm{~km}$ de la ciudad de Sinop en el norte de Mato Grosso, Brasil. Direcciones y velocidades del viento fueron recogidos diariamente por un anemómetro sónico-termómetro-dimensional, instalado en una torre a una altura de $12 \mathrm{~m}$ por encima del dosel de la selva. La dirección predominante del viento se ha caracterizado por un análisis de frecuencia de las observaciones 
diarias para cada una de las estaciones y los meses del año. En la mayoría de los meses del año hai el predominio de vientos del sur-sureste y del suroeste. Se observó que no había ninguna relación directa con el tiempo la dirección del viento, con el mismo que muestra una variación estacional, existe una relación directa con sólo la velocidad del viento. En la estación seca la dirección del viento predominante fue al sursuroeste. Ya en las estaciones secas y húmedas los vientos fluyen en todas direcciones.

Palabras clave: Velocidad del viento, dirección del viento, anemómetro.

\section{Introdução}

O movimento do ar em relação à superfície terrestre é definido como vento. É gerado pela ação de gradientes horizontais de pressão atmosférica, sobre influência do movimento de rotação da Terra, da força centrífuga ao seu movimento e do atrito com a superfície; também é influenciado pelo contraste oceano-continental e topográfico (Varejão-Silva, 2006).

O vento é uma variável meteorológica de extrema importância para as ciências agroambientais. No caso da agricultura, é conhecida a sua influência na aplicação de defensivos e em estudos voltados à propagação de doenças, polinização e práticas com quebra-ventos. Além disso, a cada dia o vento vem sendo mais utilizado como fonte de energia renovável (energia eólica).

Numa cultura vegetal, o vento pode ocasionar o efeito mecânico de agitação das árvores, dos galhos e, consequentemente, a queda de flores e frutos. Além do que, a massa de ar pode vir associada à alta energia das partículas constituintes (quentes) e com baixo teor em vapor-d'água, provocando uma rápida seca fisiológica na planta, ou, se associada à baixa energia das partículas constituintes (fria), ocasiona, nas células do vegetal, uma situação de energia interna incompatível com as funções celulares, diminuindo ou aumentando a transpiração e a absorção de $\mathrm{CO}_{2}$ (Ometto, 1981; Munhoz; Garcia, 2008).

A direção predominante do vento é a que ocorre em maior frequência e é decorrente da posição do local em relação aos centros de pressão atmosférica, variando no tempo e no espaço, sofrendo influência da orografia e de obstáculos naturais e artificiais junto ao solo. O relevo tem um efeito pronunciado, podendo definir a direção predominante do vento (Tubelis; Nascimento, 1980; Vendramini, 1986).

Essa convergência ou divergência de ventos em uma determinada faixa de latitude é, em geral, decorrente das configurações impostas pelos sistemas meteorológicos de grande escala ou até mesmo de escala sinótica às massas de ar (Silva; Britto, 2008). 
Artigo

\section{Fundamentação teórica}

No Brasil, os estudos sobre a direção e velocidade dos ventos ainda são escassos, e não retratam a distribuição espacial e temporal dos ventos nas regiões brasileiras, principalmente, nas áreas de grande interesse socioambiental, como as florestas, em especial a Floresta Amazônica.

Contudo, podem-se destacar alguns trabalhos realizados no Brasil, como o de Silva et al. (1997), que realizaram estudos sobre direção e velocidade dos ventos em Pelotas-RS e concluíram que a direção predominante dos ventos varia com a estação do ano; na primavera e no verão a direção predominante é leste (E), no outono a direção é sudeste (SE) e nordeste (NE) no inverno. Segundo estes autores, em todas as estações do ano, há uma grande incidência de ventos de direção nordeste (NE).

Galvani et al. (1999) observaram que em Maringá-PR a direção predominante dos ventos no período diurno foi nordeste, e no período noturno, sudeste (de janeiro a maio e de outubro a dezembro) e a leste (de julho a setembro). Moreno (1961) constatou que a direção normal predominante para Santa Maria (RS) é leste (E). Leste e sudeste também são as direções predominantes dos ventos em Piracicaba (Pereira et al., 2002).

Santanna et al. (2008), através de análises estatísticas, concluíram que em Cuiabá-MT, a primavera é a estação com ventos mais intensos, em oposição à estação do outono, quando são registradas as menores velocidades.

Na literatura internacional, existem inúmeros trabalhos relacionados aos ventos, por exemplo: Wanninkhof (1992) relacionou a velocidade do vento e a troca de gás acima do oceano. Ohkuma et al. (2004) elaboraram estudo da velocidade do vento em torres de transmissão no Japão, e Mulcahy et al. (2007) e Huang et al. (2010) estudaram as influências da velocidade do vento na profundidade óptica do aerossol acima do oceano.

\section{Caracterização da área de estudo}

A área em estudo está situada na Fazenda Maracaí, localizada a

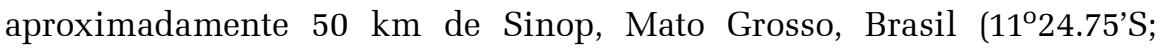
55¹9.50’O), está a $423 \mathrm{~m}$ acima do nível do mar (Figura 1). 


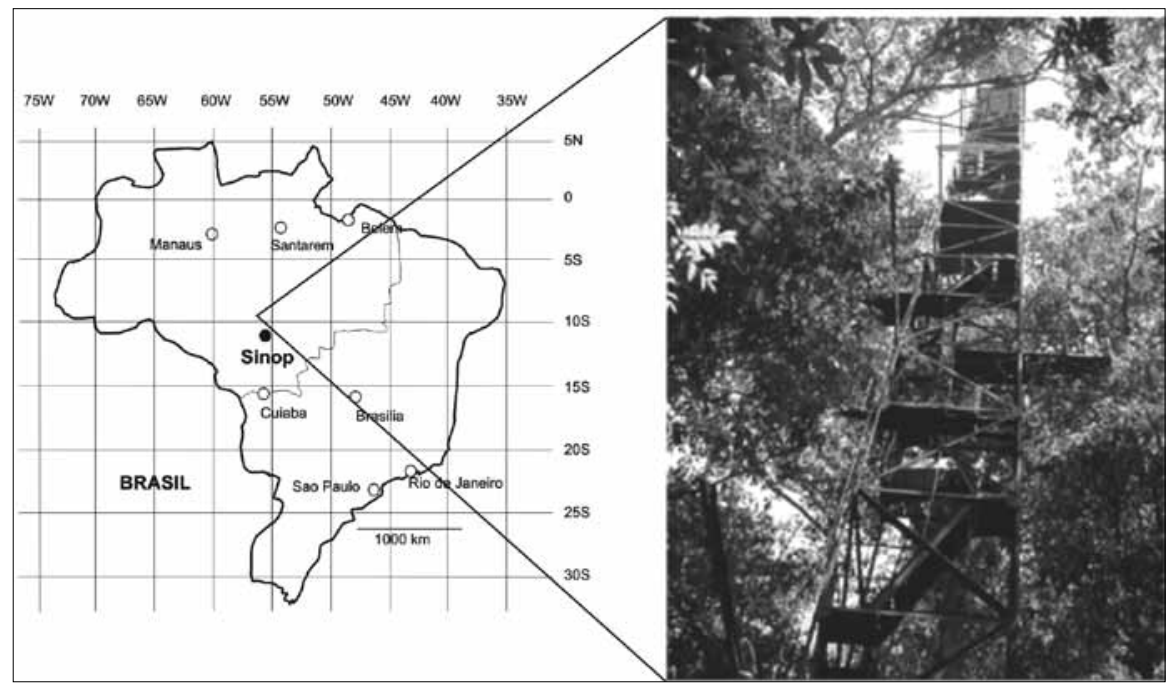

Figura 1- Localização da área de estudo.

Segundo Vourlitis et al. (2005), a área de estudo é constituída por uma floresta tropical de transição, com um dossel contínuo, composto de árvores de 28 a $30 \mathrm{~m}$ de altura. A floresta se encontra numa região de transição entre dois ecossistemas importantes: o Cerrado e a Floresta Amazônica. O clima da região segundo classificação climática de KöppenGeiger é o Aw tropical chuvoso, quente e úmido.

A vegetação local contém espécies características da floresta de transição Amazônica com espécies arbóreas, semideciduais, como Tovomita schomburkii, Qualea paraensis, e Brosimum lactescens (Miranda et al. 2005).

O solo é classificado como um neossolo quartzarênico órtico típico A moderado álico, sendo um solo extremamente arenoso, que apresenta, na profundidade de $50 \mathrm{~cm}$, uma textura com $84 \%$ de areia, $4 \%$ de silte e $12 \%$ de argila. Este solo tem elevada porosidade e drena rapidamente a água após a precipitação (dentro de 4-7 dias) (Priante Filho et al., 2004). A região possui estações bem definidas, sendo uma seca (junho a agosto), uma seca-úmida (setembro a novembro), uma úmida (dezembro a fevereiro), e uma úmida-seca (março a maio). 
Material e métodos

Neste estudo foram utilizados dados diários da direção e velocidade dos ventos cotados de meia em meia hora, considerando-se os períodos de 0 a 0:30, 0:30 a $1 \mathrm{~h}$, e assim sucessivamente até as $24 \mathrm{~h}$, no período de 2001 a 2005. As medidas foram realizadas por um anemômetro-termômetro sônico tridimensional (SWS-211/3K, Applied Technologies, Inc., Boulder, Colorado, EUA) (Figura 2), o qual possui resposta rápida de $10 \mathrm{~Hz}$, e um sistema de aquisição de dados composto por um datalogger, e por um conversor analógico/digital (datapacker) (Figura 3). Os equipamentos foram montados numa torre a uma altura de $12 \mathrm{~m}$ acima do topo da floresta, que pertence ao projeto Experimento de Grande Escala da BiosferaAtmosfera (LBA) coordenada pelo Grupo de Pesquisadores do Programa de Pós-Graduação em Física Ambiental - UFMT.

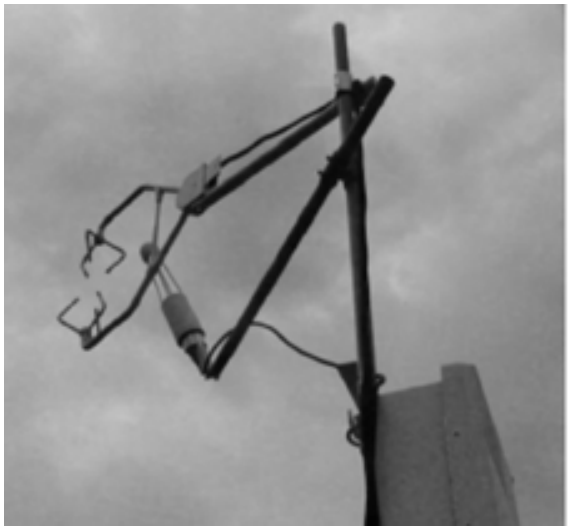

Figura 2 - Anemômetro sônico.

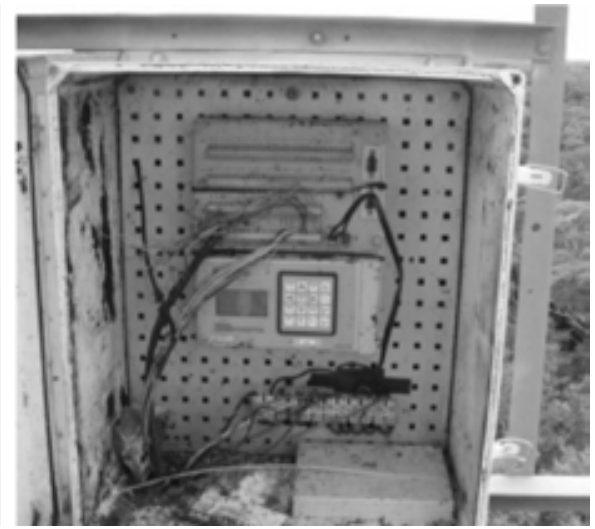

Figura 3 - Datalogger CR5000.

A direção predominante do vento foi caracterizada por meio de uma análise de frequência das observações diárias, para cada um dos meses do ano, com exceção do mês de janeiro, pois o mesmo apresentou muitas falhas, utilizando-se a seguinte expressão:

$$
f(x)=\frac{n}{N} \times 100
$$


Em que, $f(x)$ - frequência de ocorrência do vento em uma determinada direção; $n$ - número de ocorrências de uma determinada direção; N número total de observações.

Utilizou-se também do software Grapher 7, para a construção dos gráficos de direção e velocidade do vento para as quatro estações do ano, em três horários $(8 \mathrm{~h}, 14 \mathrm{~h}, 20 \mathrm{~h})$, porque a Organização Meteorológica Mundial (World Meteorological Organization - WMO) recomenda que as principais observações meteorológicas devam acontecer às $6 \mathrm{~h}, 12 \mathrm{~h}$ e $18 \mathrm{~h}$ (Greenwich Meridian Time - GMT), correspondentes às 8h, 14h, e 20h, horário local.

Resultados e discussão

A Tabela 1 apresenta as frequências da direção do vento em porcentagem para onze meses do ano, durante o período de 2001 a 2005. Analisando-se esta tabela, percebe-se que o vento de sul-sudoeste (S-SW) predominou a maior parte do ano, com exceção dos meses de dezembro, fevereiro, março e junho, em que essa predominância foi dividida com ventos de leste-sudeste (E-SE) e leste-nordeste (E-NE).

Tabela 1 - Frequência da direção do vento de fevereiro a dezembro de 2001-2005

\begin{tabular}{lcccccccccccc}
\hline DiR. Do vento & Fev. & Mar. & Abr. & Maio & Jun. & Jul. & Ago. & Set. & Out. & Nov. & Dez. & Média \\
\hline Norte-Nordeste & 14.0 & 11.0 & 4.3 & 1.7 & 3.6 & 0.6 & 1.0 & 6.6 & 9.1 & 8.3 & 12.8 & 6.6 \\
\hline Leste-Nordeste & 18.1 & 20.5 & 3.9 & 4.9 & 32.7 & 1.0 & 3.7 & 7.2 & 11.6 & 15.4 & 18.8 & 12.5 \\
\hline Leste-Sudeste & 18.6 & 25.9 & 7.5 & 5.5 & 51.0 & 1.8 & 4.7 & 6.9 & 8.6 & 9.9 & 14.3 & 14.1 \\
\hline Sul-Sudeste & 10.5 & 8.0 & 22.2 & 35.0 & 4.9 & 34.6 & 32.2 & 15.2 & 16.9 & 16.0 & 16.4 & 19.3 \\
\hline Sul-Sudoeste & 8.6 & 7.3 & 29.0 & 43.2 & 1.4 & 50.5 & 48.5 & 24.9 & 22.2 & 22.0 & 14.3 & 24.7 \\
\hline Oeste-Sudoeste & 11.9 & 10.8 & 10.1 & 5.1 & 3.1 & 5.0 & 6.4 & 18.3 & 11.6 & 11.5 & 7.4 & 9.2 \\
\hline Oeste-Noroeste & 15.5 & 13.4 & 13.7 & 2.3 & 3.1 & 5.3 & 2.1 & 13.6 & 10.1 & 8.5 & 6.5 & 8.6 \\
\hline Norte-Noroeste & 2.8 & 3.1 & 9.4 & 2.3 & 0.3 & 1.2 & 1.3 & 7.3 & 9.8 & 8.4 & 9.4 & 5.0 \\
\hline Total & 100 & 100 & 100 & 100 & 100 & 100 & 100 & 100 & 100 & 100 & 100 & 100
\end{tabular}

Pode-se verificar que, com exceção do mês de junho, no qual a maior frequência (51\%) das observações foi de ventos E-SE, nos outros meses predominou ventos S-SW, com valores de frequência, variando ente $22 \%$ 
em novembro a 50.5\% em julho, e média anual de $24.7 \%$. Os ventos de sulsudeste (S-SE) se apresentaram também muito frequentes durante todo o ano com média de 19.3\%. Segundo Nimer (1989) estes ventos de sulsudeste e sul-sudoeste são oriundos do sistema de correntes perturbadas de sul, representados pela invasão de anticiclone polar, que apresenta um comportamento bem distinto conforme se trata do verão ou inverno.

No verão, o aprofundamento e expansão do centro de baixa do interior do continente dificultam a invasão do anticiclone polar ao norte da região Centro-Oeste. Neste período, a frente polar após transpor a Cordilheira dos Andes, avança para NE, alcançando a região CentroOeste pelo sul e sudeste de Mato Grosso (Nimer, 1989). Já no inverno, o anticiclone polar invade com mais frequência a região Centro-Oeste, sendo este anticiclone mais poderoso, ele consegue transpor a Cordilheira dos Andes, atingindo o Estado de Mato Grosso com orientação NW-SE (noroeste-sudeste) caminhando para NE e SE.

A fim de avaliar a velocidade e a direção do vento predominante de acordo com os horários do dia para as estações do ano, foram realizadas as análises das Figuras 4, 5, 6 e 7. As figuras mostram as rosas dos ventos para cada uma das estações (seca, úmida-seca, seca-úmida e úmida), para cada horário (8h, 14h e 20h) do dia, utilizando o período de 2001 a 2005.

Nas figuras, pode-se notar que não houve uma relação direta dos horários com a direção do vento, tendo o mesmo apresentando uma variação sazonal. Na estação seca observa-se que a direção predominante do vento foi de sul-sudoeste. Já nas estações seca-úmida e úmida, os ventos fluíram em todas as direções, somente no horário das $20 \mathrm{~h}$ da estação secaúmida o vento teve direção predominantemente sul-sudoeste.

Na estação úmida-seca os ventos vieram da direção sul-sudoeste e sul-sudeste. O comportamento da direção e velocidade do vento para as estações seca e úmida-seca (Figuras 4 e 5) foi semelhante, devido à ação da frente polar que atua sobre a região neste período (março-agosto), e mais intensamente de maio a julho. Já nas estações seca-úmida e úmida (Figuras 6 e 7), não houve uma direção predominante do vento.

Na Tabela 2, pode-se observar que a maior velocidade do vento observada foi de 4.6 na estação seca-úmida e úmida-seca, às $20 \mathrm{~h}$ e $14 \mathrm{~h}$, respectivamente. As velocidades mínimas foram observadas as $8 \mathrm{~h}$ (período da manhã). A média da velocidade do vento mostra que em todas as estações o horário das $14 \mathrm{~h}$ apresentou o maior valor, sendo que no período da manhã e da noite os valores médios ficaram próximos. 


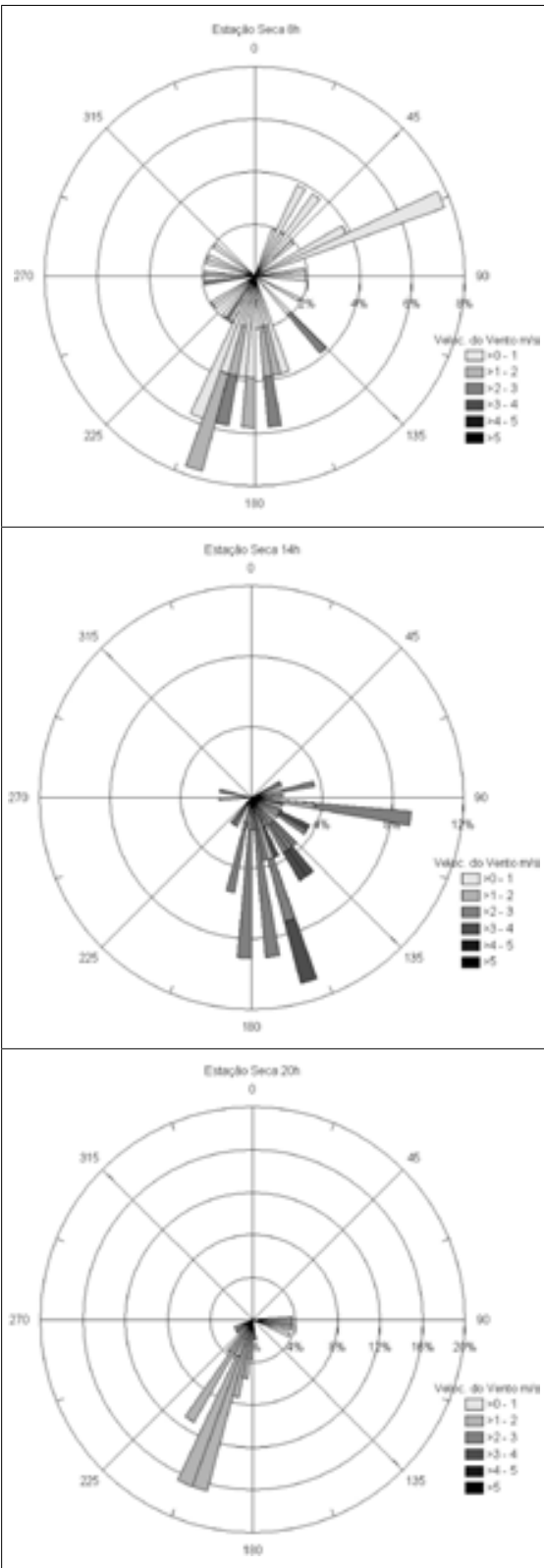

Figura 4 - Direção e velocidade do vento na estação seca.
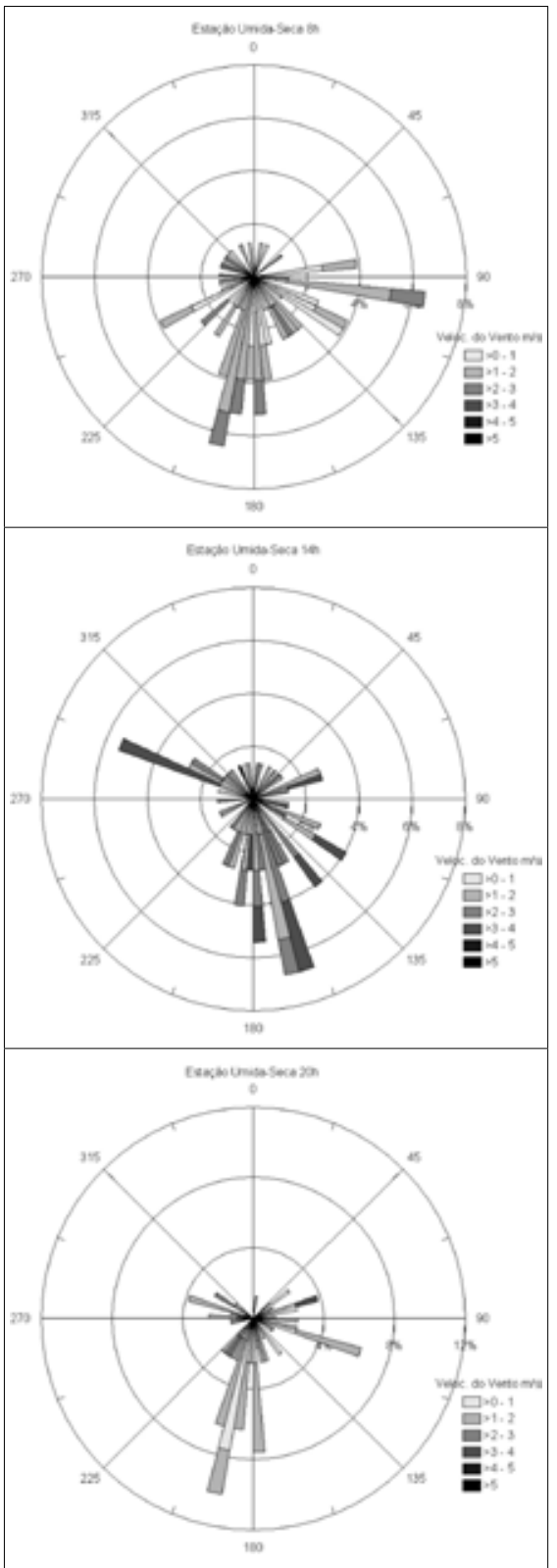

Figura 5- Direção e velocidade do vento na estação úmida-seca. 


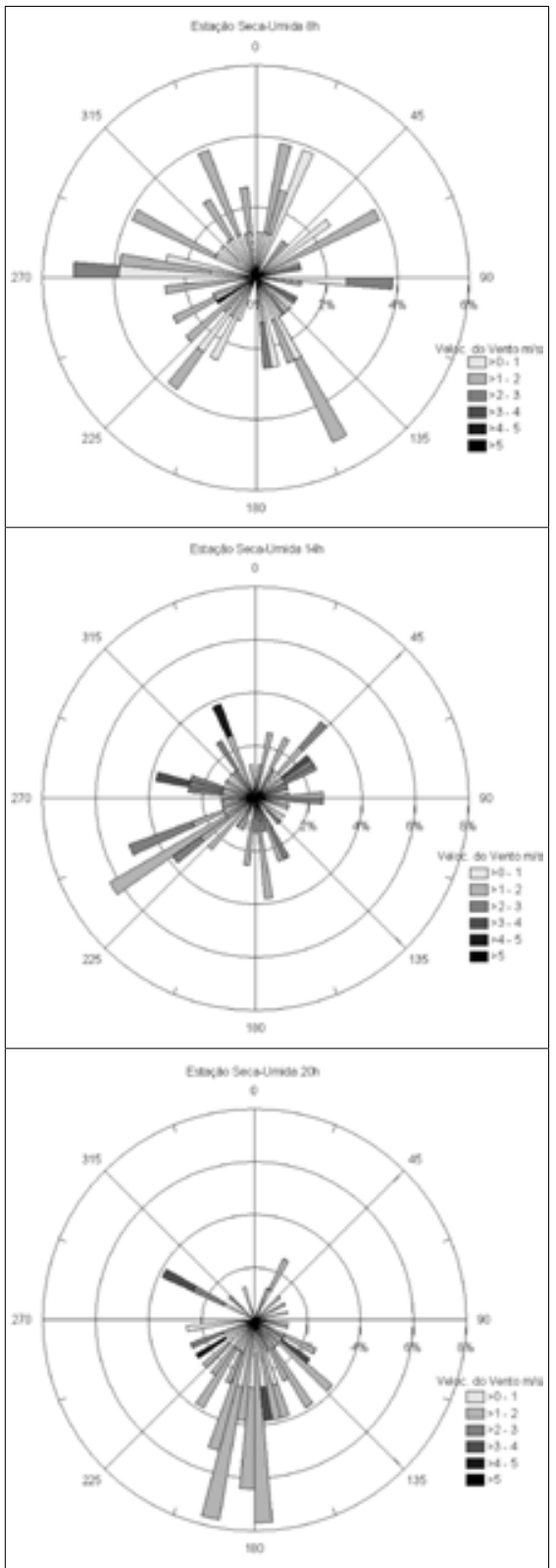

Figura 6- Direção e velocidade do vento na estação seca-úmida.

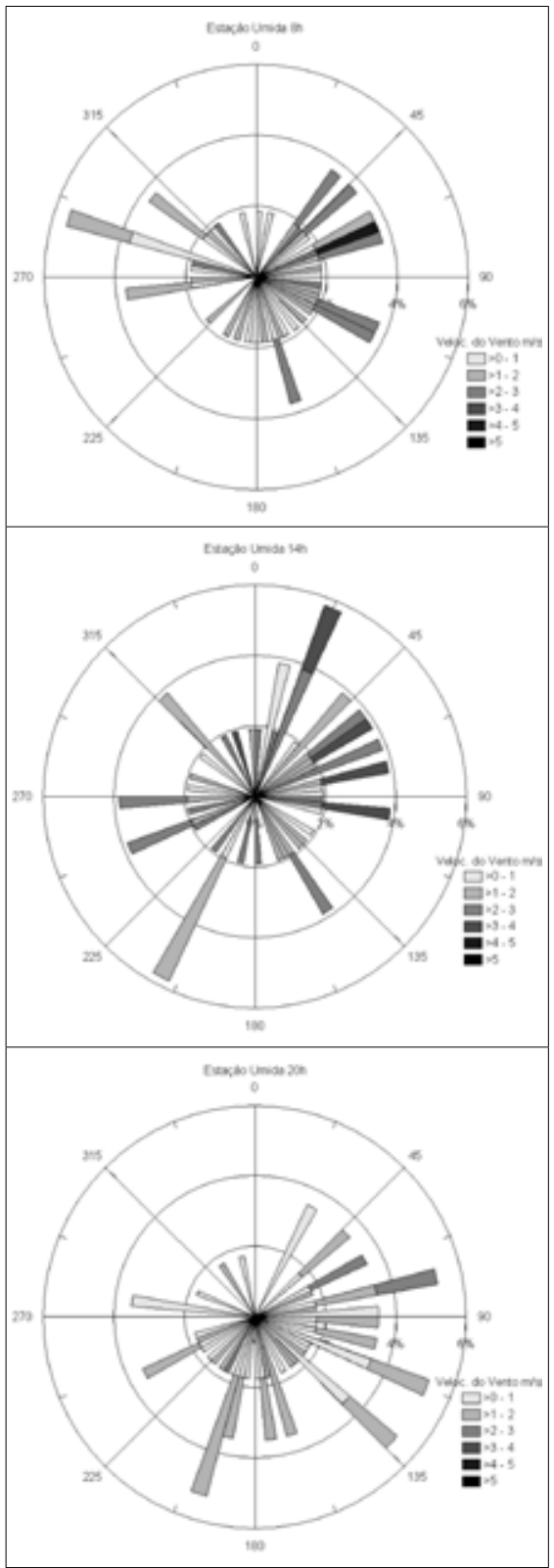

Figura 7- Direção e velocidade do vento na estação úmida. 
Com relação à diferença entre ventos diurnos e noturnos, as velocidades de vento tenderam a aumentar de valor no decorrer do dia, desde o nascer do sol, até por volta do meio da tarde, diminuindo novamente após, semelhante ao observado por Das et al. (1998) e Munhoz e Garcia (2008).

Esta tendência de ventos maiores no período da tarde deve-se ao aquecimento do solo durante o dia, o qual também vai aquecendo o ar, que ascende, sendo ocupado por um ar mais frio, gerando uma diferença térmica que, por sua vez, cria um gradiente de pressão causando o deslocamento do ar da zona de maior pressão para a zona de menor pressão. No período da manhã e da noite, como esse gradiente de pressão é menor, a velocidade do vento também é menor (Senambi, 2004 apud Munhoz; Garcia, 2008).

Tabela 2 - Velocidade do vento $(\mathrm{m} / \mathrm{s})$, média, mínima e máxima para as estações seca, seca-úmida, úmida e úmida seca às 8 h, 14h e $20 \mathrm{~h}$.

\begin{tabular}{|c|c|c|c|c|c|c|c|c|c|c|c|c|}
\hline \multicolumn{10}{|c|}{ Estações } \\
\hline & \multicolumn{10}{|c|}{ Seca } & \multicolumn{3}{c|}{ Seca-Úmida } & \multicolumn{3}{c|}{ Úmida } & \multicolumn{3}{c|}{ Úmida-Seca } \\
\hline Hs. & Méd. & Mín. & Máx. & Méd. & Mín. & Máx. & Méd. & Mín. & Máx. & Méd. & Mín. & Máx. \\
\hline $8 \mathrm{~h}$ & 0.8 & 0.2 & 2.8 & 1.2 & 0.2 & 4.2 & 1.4 & 0.2 & 4.4 & 1.2 & 0.2 & 2.8 \\
\hline $14 \mathrm{~h}$ & 2.4 & 1.2 & 3.6 & 1.7 & 0.4 & 4.1 & 2.0 & 0.5 & 3.9 & 2.0 & 0.3 & 4.6 \\
\hline $20 \mathrm{~h}$ & 1.4 & 0.8 & 2.0 & 1.3 & 0.4 & 4.6 & 1.0 & 0.3 & 2.4 & 1.1 & 0.1 & 3.2 \\
\hline
\end{tabular}

Considerações finais

As direções predominantes do vento na região de transição Floresta Amazônica e Cerrado são sul-sudeste e sul-sudoeste.

Observou-se que não há uma predominância na direção do vento para os horários de $8 \mathrm{~h}, 14 \mathrm{~h}$ e $20 \mathrm{~h}$, porém a velocidade do vento tende a aumentar no decorrer do dia e diminuir no período noturno.

Em vez da direção dos ventos apresentar uma variação horária e sazonal, apresentou apenas uma variação sazonal.

As estações seca e úmida-seca apresentaram um comportamento, tanto na direção, como na velocidade do vento, semelhantes, por causa da ação das frentes que atuam frequentemente nesse período.

Dessa forma, espera-se que o presente estudo possa fornecer subsídios aos estudos relacionados à dinâmica da floresta de transição 
Amazônia-Cerrado, visto que o vento é uma variável de grande importância no transporte de calor latente, calor sensível, umidade e $\mathrm{CO}_{2}$.

\section{Referências}

DAS, D. K. et al. Environmental Baseline Data Collection at Diablillos Property, Salta, Argentina. Argentina mining 98. Mendoza, Argentina, 1998, 15 p.

GALVANI, E.; KLOSOWSKI, E. S.; CUNHA, A. R. Caracterização da direção predominante do vento em Maringá, PR. Revista brasileira de agrometeorologia. Santa Maria, v. 7, n. 1, p. 81-90, mar. 1999.

HUANG, H.; THOMAS, G. E.; GRAINGER, R. G. Relationship between wind speed and aerosol optical depth over remote ocean. Atmospheric chemistry and physics. v. 10, p. 5943-5950, 2010.

MIRANDA, E. J.; VOURLITIS, J. L; FILHO, N. P.; PRIANTE, P. C.; CAMPELO JUNIOR, J. H.; SULI, G. S.; FRITZEN, C. L.; LOBO, F. de A.; SHIRAIWA, S. Seasonal variation in the leaf gas exchange of tropical forest trees in the rain forest-savanna transition of the southern Amazon Basin. Journal of tropical ecology, v. 21, n. 4, p. 451-460, jun. 2005.

MOREnO, J. A. Clima do Rio Grande do Sul. Porto Alegre. Secretaria da Agricultura do Estado do Rio Grande do Sul, Diretoria de Terras e Colonização, Secção de Geografia. 1961.

MULCAHY, J. P.; O'DOWD, C. D.; JENNINGS, S. G.; CEBURNIS, D. Wind Speed Influences on Aerosol Optical Depth in Clean Marine Air. Nucleation and atmospheric aerosols, n. 10, p. 1164-1168, 2007.

MUNHOZ, F. C.; GARCIA, A. Caracterização da velocidade e direção predominante dos ventos para a localidade de Ituverava-SP. Revista brasileira de meteorologia, v. 23, n. 1, p. 30-34, mar. 2008.

NIMER, E. Climatologia do Brasil. Instituto Brasileiro de Geografia e Estatística. Rio de Janeiro. 1989.

OHKUMA, T.; NAKAMURA, H.; ISHIKAWA, T.; HONGO, E.; WATANABE, T.; SHINODA, A.; KITASHIMA, T. Studies on Wind Resistant Design Using the Directional Basic Wind Speed - Recommendations for Wind Loads on Transmission Towers: A Draft. Journal of wind engineering, n. 98, p. 137-150, jan. 2004.

OMETTO, J. C. Bioclimatologia vegetal. São Paulo: Ceres. 1981.

PEREIRA, A. R.; ANGELOCCI, L. R.; SENTELHAS, P. C. Agrometeorologia: fundamentos e aplicações práticas. Guaíba: Livraria e Editora Agropecuária, 2002.

PRIANTE FILHO, N.; VOURLITIS, G. L.; HAYASHI, M. M. S.; NOGUEIRA, J. S. de, CAMPELO JR, J. H.; NUNES, P. C.; SANCHES, L.; COUTO, E. G.; HOEGER, W.; RAITER, F.; TRIENWEILER, J. L.; MIRANDA, E. J.; PRIANTE, P. C.; PEREIRA, L. C.; BIUDES, M. S.; FRITZEN, C. L.; LACERDA, M.; SULI, G. S.; SHIRAIWA, 
S.; SILVEIRA, M. Comparison of the mass and energy exchange of a pasture and a mature transitional tropical forest of the southern Amazon Basin during a seasonal transition. Global change biology, v. 10, p. 863-876, fev./mar. 2004.

SANTANNA, F. B.; ARRUDA, P. H. Z. de.; FARIA, J. L. B. de.; NOGUEIRA, J. de S. Estudo preliminar da velocidade e direção dos ventos, em Cuiabá, MT, Brasil. Revista brasileira de agrometeorologia, v. 16, n. 2, p. 175-180, ago. 2008.

SILVA, J. B.; ZANUSSO, J. F.; SILVLVEIRA, D. L. M. Estudo da velocidade e direção dos ventos em Pelotas-RS. Revista brasileira de agrometeorologia, v. 5, n. 2, p. 227-235, jun. 1997.

SILVA, D. F. da.; BRITO, J. I. B. Variabilidade do vento na bacia hidrográfica do rio São Francisco durante a ocorrência da ZCAS. Ambiência - Revista do Setor de Ciências Agrárias e Ambientais, v. 4, n. 2, p. 221-235, mai./ago. 2008.

TUBELIS, A.; NASCIMENTO, F. J. L. Meteorologia descritiva: fundamentos e aplicações brasileiras. São Paulo: Livraria Nobel, Faculdade de Ciências Agronômicas da Universidade Estadual Paulista Júlio de Mesquita Filho, 1980.

VAREJÃO-SILVA, M. A. Meteorologia e climatologia. Versão Digital 2. Recife, 2006.

VENDRAMINI, E. Z. Distribuições probabilísticas de velocidades do vento para avaliação do potencial energético eólico. 110 p. Tese (Doutorado em Agronomia) - Curso de Pós-Graduação em Agronomia, Faculdade de Ciências Agronômicas, Universidade Estadual Paulista, Unesp, Botucatu, 1986.

VOURLITIS, G. L.; NOGUEIRA, J. de S., PRIANTE FILHO, N.; HOEGER, W.; RAITER,F.; BIUDES, M. S.; ARRUDA, J. C.; CAPISTRANO, V. B.; de FARIA, J. L. B.; LOBO, F. de A. The sensitivity of diel $\mathrm{CO} 2$ and $\mathrm{H} 2 \mathrm{O}$ vapor exchange of a tropical transitional forest to seasonal variation in meteorology and water availability. Earth interactions, v. 9, n. 27, p. 1-23, dez. 2005.

WANNINKHOF, R. Relationship between wind speed and gas exchange over the ocean. Journal of geophysical research, v. 97, n. 5, p. 7373-7382, mai. 1992.

Elis Dener Lima Alves - Geógrafo, Mestre em Física Ambiental pelo Programa de Pós-Graduação em Física Ambiental pela Universidade Federal de Mato Grosso.

Stéfano Teixeira Silva - Físico, Mestre em Física Ambiental, Doutorando em Física Ambiental pelo Programa de Pós-Graduação em Física Ambiental pela Universidade Federal de Mato Grosso. 